\title{
Teoria Realista Ofensiva de Cooperação em Defesa na Unipolaridade*
}

\author{
Lucas Pereira Rezende**
}

\section{Introdução}

(ema da cooperação talvez seja um dos mais estudados na área das Relações Internacionais. As abordagens institucionalistas neoliberais, por exemplo, debruçam-se em larga medida em entender o que leva à cooperação internacional e como ela se institucionaliza (AXELROD, 1984; AXELROD; KEOHANE, 1985; HAAS, 1990; KEOHANE, 2005; KEOHANE; MARTIN, 1995; KRASNER, 1982; LIPSON, 1984; MILNER, 1992; SNIDAL, 1991; URPELAINEN, 2012). Realistas também discutem o tema, em especial via estudos das alianças, ainda que com expectativas mais reduzi-

\footnotetext{
* Artigo recebido em 12 de novembro de 2013 e aprovado para publicação em 3 de julho de 2014.

** Doutor em Ciência Política pela Universidade Federal do Rio Grande do Sul (UFRGS), professor adjunto do Departamento de Economia e Relações Internacionais e do Programa de Pós-graduação em Relações Internacionais da Universidade Federal de Santa Catarina (UFSC) e pesquisador da Rede Interinstitucional de Pesquisa em Política Externa e Regimes Políticos (Ripperp) e do Núcleo Brasileiro de Estratégia e Relações Internacionais (NERINT). E-mail: lucas.rezende@ufsc.br.
}

CONTEXTO INTERNACIONAL Rio de Janeiro, vol. 36, nº 2, julho/dezembro 2014, p. 519-548. 
das para a cooperação por essa perspectiva (GRIECO, 1990; HERZ, 1950; HYDE-PRICE, 2007; JERVIS, 1978; 1985; 1999; LAYNE, 2006; MATTES, 2012; MEARSHEIMER, 1994/95; 1995; 2001; MONTEIRO, 2011/12; MORGENTHAU, 1959; 2003; PAPE, 2005; REITER, 1994; SCHROEDER, 1976; SCHWELLER, 1994; 1997; SINGER; SMALL, 1966; SNIDAL, 1991; SNYDER, 1991; WALT, 1987; 1999; 2005; WALTZ, 1959; 1979; WILKINS, 2008; 2012; WOHLFORTH, 1999). Autores construtivistas também trabalham expectativas para a cooperação, sugerindo novas formas de socialização (BUZAN; LITTLE, 2001; BUZAN; WÆVER, 2003; HOPF, 1998; KARACAZULU; UZGÖREN, 2007; NINCIC, 2005; 2010; ONUF, 1989; RUGGIE, 1995; WENDT, 1992). Todas essas correntes, de modo geral, buscam localizar o elemento da cooperação, como princípio geral, nas relações internacionais. Alguns autores foram mais específicos no tema da cooperação em defesa e segurança internacional, e buscaram criar modelos teóricos que explicassem post hoc essa cooperação em algumas regiões específicas (COTTEY; FORSTER, 2004; DYSON, 2010; MORONEY et al., 2007; 2009; MUTHANNA, 2006; POSEN, 2006; RESENDE-SANTOS, 2007; TUCKER, 1991).

Ainda que tenham produzido avanços importantes, há limites significativos para se entender a cooperação em defesa que não são aprofundados pela literatura. Enquanto as teorias de Relações Internacionais são muito amplas, localizando as condições mais ou menos propícias para a cooperação, aqueles que buscaram especificamente tratar do elemento da cooperação em defesa e segurança internacional são específicos demais. Sendo, em geral, construídos para descrever as dinâmicas de relacionamentos específicos, esses modelos não são possíveis de serem replicados em outras regiões. Desenvolver uma nova teoria que busque não apenas localizar quando a cooperação será mais incentivada, mas também como ela deve se dar, é uma tentativa de superar esses limites apresentados pela literatura. 
A necessidade de criação de um novo modelo teórico encontra respaldo também em Mearsheimer e Walt (2013). Para os autores, as principais obras das Relações Internacionais foram esforços teóricos importantes, e a disciplina se desenvolveu em torno do desenvolvimento de pensamentos teóricos. Contudo, o papel da teoria nas Relações Internacionais tem diminuído, dando espaço para o que eles chamam de teste simplista de hipóteses.

Buscar desenvolver uma nova teoria realista para tentar entender a cooperação em defesa na América do Sul é também, de certa forma, nadar contra a corrente. Enquanto a discussão realista desponta com força em países como a China, com a chamada Escola de Tsinghua (CREUTZFELDT, 2012), o prestígio dos realistas como orientadores normativos nos Estados Unidos está em baixa (KECK, 2012). Não há estudos para medir o impacto do realismo no Brasil, mas, pela análise de Faria (2012), percebe-se a proliferação de estudos que não consideram o Estado como ator unitário e racional no país.

Reconhecemos a falha e os limites das teorias sistêmicas ao deixarem de lado as variáveis domésticas e o avanço das teorias de Relações Internacionais que levam em consideração essas variáveis. Contudo, na busca pela construção de um modelo que seja aplicável em todas as regiões do globo, incluir as variáveis domésticas como independentes seria trazer elementos reducionistas, diminuindo sua capacidade de aplicação em diferentes contextos. Ainda assim, reconhecemos que questões domésticas são sim relevantes e podem, em casos específicos, desempenhar papel crucial para o comportamento dos atores. Mas nosso objetivo aqui é entender a continuidade e o padrão via pressões sistêmicas, não as exceções.

Se lograrmos sucesso em identificar, no realismo ofensivo, a teoria das Relações Internacionais onde a cooperação é mais difícil de ser alcançada, elementos que indiquem a possibilidade da cooperação em defesa e segurança internacional, poderemos, então, sugerir um 
modelo teórico bastante amplo e com alta expectativa de poder explicativo - uma vez que poderia também ser adotado, como ponto de partida, por outras abordagens teóricas. A construção de uma nova teoria serve também para trazer um maior entendimento a respeito do comportamento de um sistema unipolar, uma vez que não há ainda uma teoria sólida de como esse sistema opera (MONTEIRO, 2011/12). Nossa proposta, nesse sentido, não é trazer uma resposta única e nem final sobre o tema, mas mostrar como as pressões sistêmicas na unipolaridade servem para incentivar a cooperação em defesa.

\section{O Realismo Ofensivo e a Unipolaridade}

Uma vez que partimos de algumas discussões já previamente bastante exploradas pela literatura, tomamos como dados alguns supostos importantes: partimos de uma abordagem realista estrutural (WALTZ, 1959; 1979), com ênfase no realismo ofensivo (MEARSHEIMER, 1994/95; 1995; 2001; RESENDE-SANTOS, 2007). Tomamos também como suposto que, após o colapso soviético, o mundo tornou-se unipolar ${ }^{1}$ (WOHLFORTH, 1999; LAYNE, 2006).

Algumas atualizações dessas perspectivas, contudo, são importantes. Monteiro (2011/12) desafia a perspectiva de que a unipolaridade seja um sistema pacífico. Apesar de reafirmar a impossibilidade de guerra entre grandes potências, a unipolaridade direciona a dois novos tipos de conflito: (1) entre a potência unipolar e outro Estado e (2) envolvendo exclusivamente outros Estados. O tipo de conflito na unipolaridade dependerá do tipo de comportamento da potência unipolar, que pode ser de: (i) dominância ofensiva, (ii) dominância defensiva ou (iii) desengajamento. ${ }^{2}$ Os dois primeiros comportamentos levam ao primeiro tipo de conflito, enquanto o desengajamento levaria ao segundo. 
A durabilidade da unipolaridade é ainda um elemento de questionamento. Para Wohlforth (1999), a unipolaridade estadunidense seria durável em virtude da questão geográfica e porque há três formas de essa configuração de poder chegar ao fim: (1) contrabalanceamento, (2) integração regional e (3) diferenças no crescimento de poder. Nenhuma dessas alternativas parecia viável para o autor. ${ }^{3}$

A unipolaridade, ao eliminar a disputa pela balança de poder global, mais do que qualquer outra configuração sistêmica, favorece a cooperação internacional e barateia os custos de manutenção da ordem. A perspectiva geral de incentivo que a unipolaridade dá aos relacionamentos multilaterais foi já trabalhada por Diniz (2006).

Ainda que deem nomes diferentes para o atual status dos Estados Unidos - Mearsheimer (2001) vai categorizá-los como único hegêmona regional e Wohlforth (1999) como potência unipolar -, as duas visões não são contraditórias - elemento também explorado bem por Diniz (2006). Enquanto Wohlforth (1999) descreve uma balança de poder global, Mearsheimer (2001) preocupa-se com a leitura das balanças de poder regionais, o que torna as duas visões complementares. Uma vez que as expectativas sistêmicas são próximas, ${ }^{4}$ para efeito do desenvolvimento da nossa teoria, faremos uso do termo potência unipolar ${ }^{5}$ como representando o ator que tenha atingido o status descrito por ambos os autores: concentração de poder tamanha que não possa ser contrabalanceado e domínio único da balança de poder regional - uma vez que a global só é possível com a maciça superioridade nuclear.

\section{A Cooperação Realista Ofensiva em Defesa na Unipolaridade}

Apresentadas as expectativas teóricas do realismo ofensivo e as dinâmicas estruturais da unipolaridade, podemos agora desenvolver, a 
partir delas, um modelo teórico que identifique as motivações dos Estados para se engajarem na cooperação nas áreas de defesa e segurança internacional.

Em primeiro lugar, é preciso definir o que cooperação quer dizer nessa área. Ações em defesa são voltadas para os Estados nacionais, como modo de preservação da integridade soberana. Segurança internacional é voltada para uma perspectiva mais sistêmica, como forma de impedir o surgimento de conflitos internacionais, qualquer que seja sua forma ou origem. Muthanna (2006) difere mais substancialmente os conceitos. Segundo o autor, cooperação em segurança é um termo mais geral, indo desde relações bi a multilaterais e envolvendo tanto civis quanto militares. Ela envolve: cooperação político-militar, o que inclui atuações multilaterais como as operações de paz da ONU; cooperação civil em segurança; e cooperação em defesa, que inclui os ministérios de defesa, agências associadas e as Forças Armadas de diferentes Estados, incluindo, mais especificamente, a questão da cooperação militar. Essa definição inclui outras formas de descrição dos alinhamentos militares do pós-Guerra Fria, como a Diplomacia de Defesa de Cottey e Forster (2004). Adotaremos o conceito de cooperação em defesa no desenvolvimento de nossa teoria, contudo, uma vez que buscamos compreender as ações que envolvem as Forças Armadas dos Estados via suas ações constabulares.

Em seguida, é preciso entender o papel do relacionamento com o polo. Ainda que os elementos regionais sejam mais perceptíveis sob a unipolaridade, o tipo de ameaças não será o mesmo. Desde a emergência da unipolaridade, os conflitos observados no sistema internacional são muito mais de origem intraestatal do que interestatal (SUTTERLIN, 1995; DOYLE; SAMBANIS, 2006). A unipolaridade não apenas elimina os conflitos guiados pela balança de poder global, mas minimiza até mesmo as disputas das balanças de poder regionais, uma vez que os Estados buscarão não contestar a ordem glo- 
bal mantida pela potência unipolar. Buscar alterar a balança de poder regional poderia ser visto pela potência unipolar como uma tentativa de busca do status de hegêmona regional, ameaçando, assim, a balança de poder global. Quanto maior o interesse da potência unipolar em uma região, maior a possibilidade de que as dinâmicas regionais reflitam as dinâmicas de poder globais (BUZAN; WÆVER, 2003). Quanto mais próxima for uma região da área de interesse estratégico vital da potência unipolar, portanto, menor será a probabilidade de que as dinâmicas de defesa dessa região sigam contra os interesses do único polo do sistema. Esse elemento vai ao encontro da expectativa de Monteiro (2011/12) sobre os dois primeiros tipos de conflitos esperados na unipolaridade - tanto a dominação ofensiva quanto a defensiva levam a conflitos entre a potência unipolar e outro Estado. Isso significa que, quanto maior o interesse da potência unipolar em uma região, mais limitados em sua capacidade ofensiva serão os Estados. O terceiro elemento de Monteiro (2011/12), do desengajamento, levaria a conflitos entre outros Estados que não a potência unipolar, em consonância com nossas expectativas de aumento da importância das balanças de poder regionais. E, mesmo nesses casos, sempre há a possibilidade de o polo global atuar ainda como balanceador offshore. Esse motivador da cooperação em defesa é explicado pelo realismo ofensivo pelo caráter calculado da agressão.

Lembremos que, sob o realismo ofensivo, a agressão não é indiscriminada, e que se comportar de maneira ofensiva significa aumentar a sua segurança (MEARSHEIMER, 2001). Dyson (2010) também afirma que o comportamento dos demais Estados será diferente na unipolaridade, uma vez que seu tipo de resposta sempre será contextual ao exercício de poder do polo. Nesse sentido, contrariar os interesses da potência unipolar em questões de segurança internacional é aumentar os riscos de um ataque - o que diminuiria, ao invés de aumentar, a capacidade de sobrevivência do atacante. Para maximizar a sua segurança, os Estados deverão seguir, ou ao menos não contrariar, os interesses da potência unipolar. 
Segundo Proença Jr. (2003, p. 2), "[c]ada sociedade, em cada tempo, configura de uma maneira particular a conversão de seus recursos em forças", o que não torna incompatível que, para maximizar o seu poder e aumentar sua segurança, devido ao novo caráter das ameaças pós-1991, os Estados se vejam compelidos a cooperar em defesa.

\section{- Dilema da Segurança e a Cooperação em Defesa}

Por que cooperar em defesa? Tradicionalmente, a não ser que motivados pelo surgimento de um Estado revisionista, as teorias realistas afirmam que cooperar em defesa é diminuir a capacidade de sobrevivência do Estado. Há, segundo Mearsheimer (2001), dois tipos de poder: real e latente - composto por elementos que podem ser transformados em poder real. Cooperar em defesa, por essa lógica, é, nos termos de Urpelainen (2012), diminuir as opções externas dos Estados justamente na área onde ele é mais sensível, no poder real, responsável imediato pela garantia de sua sobrevivência. A premissa básica do realismo ofensivo é o dilema da segurança, como elemento que leva à autoajuda e dificulta a cooperação internacional.

Segundo Mearsheimer (2001), contudo, mesmo direcionados pelo dilema da segurança, os Estados não vão querer começar uma corrida armamentista se isso não for sinônimo de uma melhora em sua posição estratégica. Como, sob a unipolaridade, a melhor opção para aumentar a segurança dos Estados é não ir de encontro aos interesses da potência unipolar, cooperar em defesa pode ter múltiplas motivações:

(1) mesmo sob a unipolaridade, os Estados se preocupam com a balança de poder regional e global, ainda que possam fazer pouco, ou nada, para alterá-las. Mesmo assim, Mearsheimer (2001) afirma que, antes de se preocuparem em projetar poder, os Estados de segunda linha se preocuparão em se defender dos maiores. Nesse senti- 
do, cooperar em defesa pode ser um caminho para que esses Estados possam manter, modernizar e, eventualmente, até mesmo aumentar seus recursos de poder sem, contudo, (a) desencadear uma corrida armamentista que não possam manter ou (b) despertar a discordância da potência unipolar. A unipolaridade não elimina, mas controla, como nenhuma outra distribuição de recursos, os efeitos do dilema da segurança (DYSON, 2010).

(2) O realismo ofensivo afirma também que aliados influenciam nos gastos e tipos de investimento em defesa. Quanto mais ricos forem os aliados, menos gastos precisarão ser feitos em defesa. Levando em consideração a discussão sobre a mudança do perfil das alianças pós-1991 feita por Wilkins (2012), e reconhecendo que o atual padrão de aproximação dos Estados é o de um alinhamento, que leva em consideração as expectativas dos atores sobre o grau de cooperação futura, diferente das alianças, menos estáveis, o comportamento maximizador dos Estados, orientados pelo realismo ofensivo sob a unipolaridade, tem sido direcionado para as parcerias estratégicas (COTTEY; FORSTER, 2004; DYSON, 2010; US CONGRESS, 1990). Nesse sentido, cooperar em defesa pode servir para melhorar a posição estratégica dos Estados de segunda linha frente à potência unipolar sem terem que gastar tanto. Uma vez que o balanceamento não é possível sob a unipolaridade, as parcerias estratégicas são uma forma de alinhamento que contribui para a melhoria da posição estratégica dos seus participantes, aumentando a sua capacidade de sobrevivência via a melhor forma possível de maximização de seus recursos. Muthanna (2006) afirma que, desde que associados à política externa, arranjos cooperativos em segurança podem contribuir para os objetivos de segurança e estratégicos dos Estados.

(3) Uma vez atingido o status de hegêmona regional, ${ }^{6}$ Mearsheimer (2001) afirma que esse ator vai trabalhar para que não surjam hegemonias regionais em outras partes do mundo. Preferencialmente, diz a teoria, o hegêmona vai deixar que as balanças de poder regionais 
atuem, optando por agir como balanceador offshore caso as dinâmicas regionais não sejam suficientes para conter o surgimento de um novo candidato a hegêmona regional. Essa expectativa está em acordo com a estratégia de desengajamento, tal qual descrita por Monteiro (2011/12), que levaria a um aumento da importância das balanças de poder regionais na unipolaridade e a conflitos envolvendo outros Estados que não o polo global. Já para Wohlforth (1999), a fim de evitar atrasos ou falhas na contenção de Estados revisionistas, a presença da potência unipolar será mais frequente nas demais balanças de poder, indo ao encontro das estratégias de dominância ofensiva e defensiva de Monteiro (2011/12), o que favorece mais, em termos de pressão estrutural, a emergência de conflitos entre a potência unipolar e outro Estado.

Monteiro (2011/12) afirma que, mesmo que a unipolaridade incentive a potência unipolar a começar nessa configuração de poder através da dominância ofensiva, é possível que, com o tempo, ela altere o seu comportamento em direção ao desengajamento. Enquanto autores como MacDonald e Parent (2011) defendem o desengajamento, apresentando seus casos bem-sucedidos ao longo da história - ainda que em outras configurações de poder que não a unipolaridade -, Brooks et al. (2012/13) dizem que claramente essa estratégia não deve ser procurada pelos EUA. Se a estratégia atual, de maior presença global, é o "diabo que nós conhecemos”, o desengajamento é o "diabo que nós não conhecemos", que "apresentaria riscos e custos muito maiores" (BROOKS, 2012/13, p. 10).

Qualquer que seja a expectativa de comportamento a ser seguida, pelas duas possibilidades acima descritas, é de interesse do polo evitar o surgimento de Estados revisionistas nas balanças de poder regionais. Nesse sentido, a cooperação em defesa nas balanças de poder regionais, mesmo naquelas sem a presença da potência unipolar, funciona como instrumento em favor do polo global, uma vez que serve para conter eventuais candidatos a hegêmonas regionais. As dinâ- 
micas das balanças de poder regionais servirão como indicadores importantes para a manutenção da ordem pela potência unipolar, indicando até mesmo o momento em que seja necessária alguma medida de balanceamento offshore ou onde possam operar via desengajamento. Os meios de accountability, de provimento de informações e as dinâmicas cooperativas servirão como forma natural de contenção de Estados revisionistas nas balanças de poder regionais. Caso as dinâmicas cooperativas comecem a favorecer um Estado mais do que outros, por consequência do desengajamento, a própria preocupação com os ganhos relativos levará a um movimento balanceador regional. Se nem mesmo a dinâmica das balanças de poder regionais for suficiente para conter um candidato a hegêmona regional, a potência unipolar sempre poderá agir, como última medida, como balanceador offshore.

Sob a perspectiva da potência unipolar, os elementos da Nova Diplomacia de Defesa também justificam a cooperação em defesa pela lente do realismo ofensivo. O engajamento estratégico com antigos ou potenciais inimigos, o espalhamento da democracia como forma de garantir o estabelecimento de regimes aliados e o desenvolvimento em capacidades para engajamento em operações de paz são exemplos de Cottey e Forster (2004) nesse sentido. Todos esses elementos facilitam o controle de eventuais ameaças estatais via cooperação, barateando e simplificando a manutenção da ordem unipolar e justificando a cooperação em defesa por razões do realismo ofensivo.

(4) Mesmo em processos de cooperação em defesa que levem à formação de instituições - alinhamentos mais sólidos e limitados em escopo -, a cooperação em defesa por razões do realismo ofensivo é possível, desde que forme instituições que contribuam para uma dinâmica mais ampla de fortalecimento da capacidade de ação do Estado. Nesse sentido, as disposições realistas que Cepik (2010, p. 61-62) identifica em instituições internacionais, geradas e mantidas pela cooperação em defesa, são: 
1) as instituições internacionais são criadas por Estados interessados em poder; 2) a cooperação institucionalizada no domínio internacional ainda é complexa; 3) existem conflitos distributivos ("ganhos relativos desiguais"), independentemente da quantidade de informações fornecidas pelas instituições internacionais; 4) o desenho institucional pode reduzir, mas não eliminar, as dificuldades associadas com as metas de integração e cooperação em segurança.

Isso significa que as instituições devem servir ao propósito de maximização trazido pelo realismo ofensivo, favorecendo, e não diminuindo, a capacidade estatal - do contrário, irá de encontro à teoria e funcionará como elemento de diluição do poder do Estado.

Diferentemente, portanto, do que a literatura realista em geral aponta, a cooperação em defesa na unipolaridade é não apenas incentivada para a manutenção do status privilegiado da potência unipolar, mas também para os demais Estados do sistema. Por ser mais difícil de ser atingida do que outras formas de cooperação, uma vez que lida diretamente com o poder real dos Estados, a cooperação em defesa pode, também, servir como um elemento desencadeador de outras formas de cooperação. Resende-Santos (2007, p. 9) afirma que os Estados copiam as práticas bem-sucedidas dos outros não apenas em questões militares, mas também em "práticas econômicas, regulatórias, administrativas e, até mesmo, constitucionais”. Há, portanto, uma utilidade normativa importante para se entender as razões e condições para a cooperação em defesa na unipolaridade, uma vez que pode servir para uma ampliação da agenda política dos Estados envolvidos - desde que respeite a premissa básica do realismo ofensivo, de maximizar o poder do Estado para melhor garantir a sua sobrevivência. 
Teoria Realista Ofensiva de Cooperação em

Defesa na Unipolaridade

\section{As Variáveis Independentes da Cooperação Realista Ofensiva em Defesa na Unipolaridade}

Se os Estados tiverem a cooperação em defesa como um meio de maximizarem o seu poder, aumentando a sua capacidade de sobrevivência, devem atentar para as seguintes variáveis: (1) a distribuição de recursos entre as unidades do sistema; (2) o tipo de cooperação; (3) o efeito da cooperação na capacidade estatal; (4) o desenho das instituições geradas; e (5) a emulação de casos bem-sucedidos.

(1) A distribuição de recursos entre as unidades do sistema. Esse é o principal elemento que interferirá no modo como a cooperação em defesa será organizada. Isso significa que a cooperação militar será dependente do contexto político em que esteja inserida. Em primeiro lugar, o suposto teórico do nosso modelo é, para o sistema global, que haja a unipolaridade. Isso significa que quaisquer formas de cooperação em defesa devem ser guiadas pelo princípio máximo de concordância, ou, ao menos, da não discordância, da potência unipolar. Outras polaridades terão outros incentivos sistêmicos diferentes. Na bipolaridade, esse incentivo previamente descrito existirá apenas para os membros das alianças de cada um dos polos. Na multipolaridade global, seja ela equilibrada ou desequilibrada, os efeitos sistêmicos indicarão a cooperação em defesa dentro do modelo tradicional das alianças, tal qual descrito pela teoria clássica da balança de poder.

Estando a balança de poder global definida, as balanças de poder regionais terão maior importância para a compreensão da cooperação em defesa sob a unipolaridade. Esse elemento dependerá também da estratégia adotada pela potência unipolar, se de dominação ofensiva, defensiva ou de desengajamento. Quanto maior a presença, maior a possibilidade de envolvimento da potência unipolar nas dinâmicas regionais (MONTEIRO, 2011/12). 
Urpelainen (2012) afirma que as incertezas sobre o campo externo vão afetar a cooperação profunda em duas situações: (a) quando a frequência de Estados com poucos recursos (chamados por ele de Estados vulneráveis) for alta e (b) quando a cooperação profunda assimétrica de fato diminui as posições de barganha desses Estados. Isso significa que sistemas com muitos Estados vulneráveis, pela própria baixa capacidade estatal, não conseguirão incentivar a cooperação em defesa, uma vez que não terão condições elementares capacidades mínimas de autonomia do Estado - para levar adiante tal cooperação. Nesses casos, abrir mão de um mínimo de autonomia pode representar dar fim à própria capacidade de sobrevivência desses Estados. Seria o caso de multipolaridades equilibradas onde a capacidade estatal é quase nula. Poderíamos, para evitar confusões com as dinâmicas da multipolaridade equilibrada, chamar esses casos de nulidade polar. Aqui, não há polos claros no sistema, devido à baixa capacidade dos Estados envolvidos.

De igual modo, quando a distribuição de recursos for excessivamente assimétrica na balança de poder regional, a cooperação em defesa pode significar a perda total de autonomia dos Estados vulneráveis frente aos principais polos do sistema regional. Esse é o caso das multipolaridades desequilibradas. Cooperar em segurança, nesses casos, seria o sinônimo de incentivar o candidato a hegêmona regional em sua empreitada - desestabilizando ainda mais o sistema e, por parte dos demais atores envolvidos, diminuindo, e não aumentando, a sua capacidade de sobrevivência -, o que iria contra as expectativas do realismo ofensivo. Sob a perspectiva da potência unipolar, a multipolaridade desequilibrada é o mais arriscado modelo de balança de poder, uma vez que há um candidato a hegêmona regional que, se bem-sucedido, pode incomodá-la na balança de poder global. Nesse sentido, nas balanças de poder regionais, a nulidade polar e a multipolaridade desequilibrada são os modelos que não incentivam estruturalmente a cooperação em defesa. 
Tal qual na balança de poder global, os sistemas que mais estimulam a cooperação em defesa nas balanças de poder regionais são a bipolaridade, uma vez que forma dois grandes blocos de alianças, e a unipolaridade, que, tal qual no sistema global, leva os demais atores a se alinharem naturalmente com o polo regional-já que não há a possibilidade de uma aliança balanceadora.

Há uma diferença marcante, contudo, da cooperação nas balanças de poder regionais e a global. Ao tratarmos das dinâmicas regionais sob a unipolaridade, a configuração regional multipolar equilibrada pode também incentivar a cooperação em defesa - diferentemente do que é visto na balança de poder global. Essa distribuição de poder pode servir como ferramenta para os Estados engajados na cooperação em defesa para:

(i) conter o surgimento de um candidato a hegêmona regional. A accountability e a troca geral de informações possibilitariam aos atores identificar a emergência de revisionistas. Na eventualidade de um Estado concentrar sobremaneira os ganhos da cooperação, a lógica da preocupação com os ganhos relativos levará à formação de uma aliança balanceadora para a contenção do candidato a hegêmona regional, reestabilizando o sistema. Essa possibilidade, de maior influência das balanças de poder regionais, será maior nos casos de desengajamento (MONTEIRO, 2011/12) ou de maior desinteresse da potência unipolar na região. Caso a aliança falhe, ou se mostre fraca demais, sempre existe o recurso à potência unipolar de agir como balanceador offshore, uma vez que trabalhará sempre de forma a evitar o surgimento de outro hegêmona regional; e

(ii) aumentar o grau da capacidade estatal geral das unidades envolvidas. Se, sob cooperação, todas aumentam em proporção semelhante os seus recursos, não há um aumento do dilema da segurança dessas unidades no plano regional, e sua posição relativa frente à potência unipolar global é incrementada. Contanto que esse aumento de 
recursos não represente uma tentativa de formação de uma aliança balanceadora no plano global - o que é pouco provável, se não impossível, na unipolaridade -, tal incremento relativo não tem motivos para levar à oposição da potência unipolar global. Os atores, por motivos do realismo ofensivo, cooperam sob a multipolaridade equilibrada para aumentarem a sua capacidade de sobrevivência frente tanto à potência unipolar global quanto frente aos demais atores dos sistemas global e regional. Jervis (1978) afirma que mesmo as potências do status quo podem, em algum momento, verem-se insatisfeitas com ele e resolverem alterá-lo, ameaçando os demais Estados protegidos pela ordem vigente - o que justifica a preocupação dos demais Estados em buscarem aumentar a sua segurança frente à potência unipolar - ainda que isso não seja suficiente para um balanceamento a curto ou médio prazo.

(2) O tipo de cooperação. Urpelainen (2012) mostra-nos que a cooperação pode ser rasa ou profunda. Quanto mais perto da profunda, mais serão necessários ajustamentos políticos difíceis de serem revertidos, o que aumenta a dependência dos atores de uma cooperação contínua, reduzindo, portanto, as opções externas dos envolvidos. Se o objetivo dos Estados no realismo ofensivo é maximizar a sua segurança, devem ser evitadas situações em que a cooperação profunda contínua em defesa possa levar a uma diminuição, e não a um aumento, da sua segurança. A cooperação profunda pode representar um aumento desproporcional de dependência, o que enfraquecerá a capacidade do Estado de agir sozinho quando necessário. Cooperar em defesa, nesses casos, seria trabalhar contra o princípio realista ofensivo de maximização da sobrevivência. Mattes (2012) também afirma que a expectativa de oportunismo nas alianças também incidirá sobre o tipo de cooperação. Nesse sentido, modelos de alinhamento em que a possibilidade de oportunismo seja grande, e que tal oportunismo possa representar uma mudança brusca da balança de poder regional em favor de um ator específico, devem ser evitados na cooperação de 
defesa, uma vez que seriam sinônimo de perda, e não da maximização da segurança do Estado. O tipo de cooperação em defesa deve ser guiado pelo princípio do dilema da segurança: deve ter elementos distributivos tais que possibilitem o aumento conjunto dos recursos dos envolvidos, sem privilegiar nenhuma unidade em detrimento das demais. Tal privilégio pode levar a um desequilíbrio da balança de poder regional, desencadeando um movimento balanceador local ou, até mesmo, global, pelo envolvimento da potência unipolar.

(3) O efeito da cooperação na capacidade estatal. A racionalidade do Estado e o seu desejo de sobreviver são supostos fundamentais do realismo ofensivo. Desse modo, arranjos cooperativos que levem a uma diminuição da capacidade do Estado devem ser evitados - a não ser que esse seja claramente o objetivo. ${ }^{7}$ Nesse caso, contudo, o Estado estará agindo contra as expectativas do realismo ofensivo, uma vez que voluntariamente estará abrindo mão do seu desejo de sobrevivência. A cooperação em segurança motivada pelo realismo ofensivo deve, portanto, contribuir para aumentar a capacidade Estatal, e não diminuí-la. A cooperação em segurança, nesse sentido, deve atender aos requisitos sugeridos por Muthanna (2006, p. 12): (i) aumentar a segurança do Estado tanto no ambiente interno quanto no externo; (ii) aumentar os recursos militares de defesa do Estado; (iii) não prejudicar nem a capacidade dos militares do Estado de agirem sem os parceiros, se necessário, nem os interesses da segurança nacional; (iv) que se relacione com os recursos necessários para as ações de qualquer alinhamento em que o Estado já esteja envolvido; (v) que seja compatível e não ameace outros vínculos multilaterais preexistentes.

(4) O desenho das instituições geradas. O realismo ofensivo parte do suposto que instituições internacionais são uma extensão do interesse dos Estados (MEARSHEIMER, 2001). Logo, contanto que contribuam para a maximização do poder dos Estados para garantir melhor a sua sobrevivência, as instituições serão elementos importantes nas relações internacionais. Parte-se do suposto que: (a) as institui- 
ções internacionais são criadas por Estados interessados em maximizar o seu poder, (b) a cooperação internacional institucionalizada é ainda complexa, (c) a preocupação com os ganhos relativos desiguais existe, e independe das informações trazidas pelas instituições internacionais, e (d) o desenho institucional pode diminuir, mas não mitigar, os problemas relacionados aos objetivos de integração regional e cooperação em defesa (CEPIK, 2010).

As instituições vão contribuir para a cooperação em defesa, nesse sentido, se: (i) aumentarem os ganhos da cooperação mútua e/ou diminuição dos custos caso um Estado coopere e outro não; (ii) diminuírem os incentivos para defecção através da diminuição dos ganhos da trapaça e/ou do aumento dos custos da não cooperação; (iii) fizerem qualquer coisa que aumente a expectativa do outro cooperar (JERVIS, 1978); (iv) houver uma conexão do desenho institucional com a balança de poder regional e a global. Quanto maiores as pressões do dilema da segurança, maior a possibilidade de a cooperação em defesa levar a instituições mais formais, calcadas na lógica das alianças. Essas instituições, contudo, têm um incentivo a não se manterem sob o mesmo desenho institucional caso as pressões sistêmicas mudem. Quanto menores as pressões do dilema da segurança, maior a possibilidade de os alinhamentos serem mais institucionalmente soltos (WILKINS, 2012). Em qualquer dos casos, contudo, as instituições geradas devem servir para aumentar a maximização do poder do Estado, a fim de aumentar a sua segurança.

(5) Emulação de casos bem-sucedidos. É uma premissa do realismo ofensivo que Estados copiam estratégias bem-sucedidas, como forma de maximizar o seu poder (WALTZ, 1979; MEARSHEIMER, 2001). Segundo Resende-Santos (2007, p. 9),

[e]mulação militar é a imitação deliberada por um Estado de qualquer aspecto do sistema militar de outro Estado que recaia sobre seu próprio sistema militar. Essa emulação traz as Forças Armadas do emulador (ou componentes es- 
pecíficos delas) a uma correspondência razoavelmente próxima ao modelo sendo emulado. A emulação, como uma forma genérica do comportamento estatal, é a imitação voluntária, proposital e sistemática por um Estado de técnicas e práticas de outro.

Tal velocidade de cópia depende tanto de fatores sistêmicos, como o nível de ameaça com que os Estados se deparam (RESENDE-SANTOS, 2007), quanto de fatores internos, como o grau de vulnerabilidade externa de um Estado (DYSON, 2010; POSEN, 2006; HYDE-PRICE, 2007). A emulação dos casos bem-sucedidos deverá ser uma condição a ser buscada apenas se as demais variáveis também forem espelháveis ao caso em questão. A emulação de casos bem-sucedidos de cooperação em defesa que desconsidere as demais variáveis apresentadas, ou mesmo as emule de maneira equivocada, poderá levar a uma diminuição da maximização do poder do Estado, operando, dessa forma, contra os princípios do realismo ofensivo. A emulação só deve ser perseguida caso todas as variáveis acima descritas sejam análogas.

Ainda que nossa proposta seja a construção de um modelo teórico estrutural, temos ciência de que variáveis internas importam. Talvez não como elementos explicativos abrangentes, como a pressão sistêmica. Ainda assim, optamos por apresentar, como elementos de pesquisa adicionais ao modelo teórico principal, duas variáveis internas ${ }^{8}$ que contribuam para o propósito de maximização do poder do Estado com o intuito de aumentar a sua segurança via cooperação em defesa. Essas variáveis estiveram presentes em todos os modelos teóricos específicos que encontramos, por isso optamos por incluí-las como elementos incrementais - ainda que não necessariamente explicativos generalizadores. São elas: (a) criar formas de comunicação interinstitucionais domésticas que favoreçam a coesão dos processos de formulação e condução das tomadas de decisão na coope- 
ração em defesa, o que inclui a promoção dos relacionamentos entre civis e militares. Esse elemento tem reflexo importante para a abordagem estrutural: contribui para a criação da unidade do Estado como ator nas relações internacionais, fortalecendo sua capacidade de resposta e, portanto, sua habilidade em transformar as novas formas de recursos, quaisquer que sejam elas, em maior segurança; e (b) o grau de vulnerabilidade externa, medido pelas variáveis domésticas de constituição de poder, que depende de elementos como: "[1] tamanho do território e da população, [2] posição geográfica, [3] capacidade produtiva" (DYSON, 2010, posição 2640), além dos elementos trazidos pelo realismo neoclássico, como o que Dyson (2010) chama de autonomia executiva.

\section{Conclusão}

A teoria realista ofensiva de cooperação em defesa na unipolaridade indica que há razões, sob determinadas circunstâncias, que justificam a cooperação em defesa pelos Estados. Uma vez que a expectativa do realismo ofensivo é a maximização do poder dos Estados, diferentes estruturas levarão a diferentes formas de maximização de poder.

Nossa nova proposta teórica para a compreensão do porquê a cooperação em defesa se tornou um fenômeno tão observado, de maneiras tão distintas, no pós-Guerra Fria busca trazer uma construção teórica ampla que permita compreender (1) a motivação dos Estados para cooperar em defesa; (2) as variáveis independentes que afetam a cooperação em defesa; (3) um modelo amplo de cooperação em defesa que possa ser replicado em diferentes regiões do mundo. Partimos do realismo ofensivo, teoria das Relações Internacionais em que a cooperação é vista como mais difícil de ser atingida, uma vez que, identificadas as razões para cooperar via realismo ofensivo, outros modelos em que a cooperação é vista como mais possível de acontecer, como o institucionalismo neoliberal ou o construtivismo, poderiam partir dessa análise para suas agendas de pesquisa. 
Não sendo possível o balanceamento contra a potência unipolar, as pressões estruturais serão para a contenção de Estados revisionistas tanto na balança de poder global quanto nas regionais. Nesse cenário, tentativas de alteração das balanças de poder regionais serão punidas pelo sistema. A forma como os Estados poderão, então, maximizar o seu poder é a cooperação em defesa, uma vez que tal cooperação supõe uma concordância - ou ao menos não discordância - da potência unipolar. Guiados pelo dilema da segurança, os Estados se preocuparão com os ganhos relativos, motivo pelo qual qualquer tentativa de nova hegemonia regional será contida pelos demais Estados. Nesse sentido, a cooperação em defesa deve prover não apenas aumento da capacidade estatal individual, mas também elementos distributivos que não desencadeiem uma corrida armamentista no plano regional, nem um balanceamento offshore por parte da potência unipolar. Cooperar em defesa serve, nesse sentido, para aumentar a posição relativa dos Estados participantes tanto perante os demais Estados quanto perante a potência unipolar, sem, contudo, aumentar as pressões do dilema da segurança. Esse suposto reafirma o princípio egoísta dos Estados, de buscarem maximizar o seu poder para melhor garantir a sua sobrevivência, mas mostrando que novos tempos exigem novas formas de maximização de poder.

\section{Notas}

1. A noção de polo utilizada aqui é a definida por Schweller (1998). Polo é aquele país que detém mais de $50 \%$ dos recursos dos dois Estados imediatamente inferiores a ele na escala de recursos.

2. Optamos pelo vocábulo desengajamento como mesma tradução dos termos em inglês disengagement, utilizado por Monteiro (2011/12), e retrenchment, utilizado por Brooks et al. (2011/12) e por MacDonald e Parent (2011).

3. E, a nosso ver, essas opções continuam inviáveis. A crise europeia, iniciada em 2008 e ainda em curso em 2013, mostrou bem as fragilidades do processo de 
integração da União Europeia. O crescimento acelerado chinês mostrou, em 2012, indicadores de que não continuaria assim tão acelerado (ORLIK; DAVIS 2012a; 2012b). Mesmo que o crescimento chinês da década anterior seja retomado, a China possui desafios regionais (seu forte crescimento poderia desestabilizar a balança de poder regional, aumentando instabilidades com atores importantes, tais como Índia, Japão, Coreia do Sul e Rússia) e internos (tais como a distribuição interna de renda, sua grande população e seu envelhecimento cada vez maior, pressões por mudanças políticas, a fragmentação do Estado, a pressão demográfica sobre os grandes centros, entre outros) grandes antes de se tornar uma potência de primeira linha. Além desses elementos, não há indícios de interesse de balanceamento por parte daquelas potências de segunda linha em ascendência, como os países do BRICS, uma vez que Brasil, Rússia, Índia, China e África do Sul crescem sob uma ordem mantida pelos EUA - ou seja, beneficiam-se desse cenário. Uma possibilidade mais plausível de fim da unipolaridade, não levantada por Wohlforth (1999), seria uma revolução tecnológica que tornasse inúteis as armas nucleares. Essa possibilidade é trabalhada por Cepik et al. (2009) sobre o advento das armas de energia direta. Segundo os autores, essa tecnologia, uma vez que totalmente desenvolvida, poderia tornar inútil o arsenal nuclear dos EUA (e, naturalmente, de todos os que detêm essa tecnologia), o que poderia levar o mundo a um ambiente multipolar rapidamente. A novidade mais notável, contudo, foi o revisionismo russo observado, a partir de meados de 2014, na crise ucraniana. Ainda que com PIB distante do chinês e do estadunidense, a Rússia é a segunda colocada em termos de recursos militares. Seu revisionismo no caso ucraniano é ímpar nesse último quarto de século, e, pós-1990, é o movimento mais marcante em direção ao fim da unipolaridade. Se confirmadas as novas parcerias estratégicas russo-chinesas em direção a um isolamento europeu e a retração da presença dos EUA nessas balanças de poder, poderemos afirmar, com segurança, o fim da unipolaridade - o que não invalida essa proposta teórica aqui apresentada como explicativa para o padrão de relacionamento entre Estados nos últimos 25 anos.

4. A principal diferença entre as expectativas sistêmicas de Wohlforth (1999) e Mearsheimer (2001) está no comportamento do principal ator do sistema. Enquanto o primeiro afirma que um maior intervencionismo da potência unipolar seria esperado para manter a ordem internacional, o segundo afirma que o comportamento mais benéfico para o hegêmona regional seria deixar a dinâmica das balanças de poder regionais atuar por si só, recolhendo-se à sua região e agindo como balanceador offshore apenas quando as dinâmicas regionais não parecessem dar conta de conter a emergência de um novo hegêmona regional. Ambas têm efeitos colaterais. A expectativa de Wohlforth (1999) pode levar ao chamado overstreach imperial, que é a corrosão do poder da potência unipolar pela presença maciça além-mar (LAYNE, 2006). A expectativa de Mearsheimer (2001), trabalhada pelo próprio autor, pode levar a um problema de atraso 
na contenção de um novo hegêmona regional, caso o balanceamento offshore venha tarde demais ou seja incapaz de reverter o candidato revisionista.

5. A escolha do termo potência unipolar em detrimento de hegêmona regional não é aleatória. Em textos posteriores, o próprio Mearsheimer incorpora o termo unipolaridade para descrever o atual sistema internacional, como em Mearsheimer e Walt (2013). Por essa razão, cremos que potência unipolar é mais abrangente e academicamente citado.

6. Ainda que tenhamos optado por fazer uso do termo potência unipolar, nesse ponto se faz necessário recapitular a discussão de hegemonia regional de Mearsheimer (2001).

7. Há situações em que o objetivo do Estado pode ser deixar de existir: quando dá origem a uma unidade maior - um outro Estado. Foi o caso, por exemplo, dos Estados nacionais que abriram mão de sua soberania para participarem da União Soviética, ou dos Estados independentes que, após a guerra civil estadunidense, uniram-se e deram origem aos Estados Unidos. Ainda que a União Europeia não esteja em seus melhores dias, uma das possíveis consequências de seu processo de integração é a constituição de um Estado Europeu, que subjugue os atuais Estados em uma única soberania. Se isso vier a acontecer, foi porque os atuais Estados soberanos europeus abriram mão, voluntariamente, do seu objetivo maior de sobreviverem como unidades autônomas do sistema.

8. Temos ciência de que não são apenas essas duas variáveis que podem influenciar, pelo caráter doméstico, o fortalecimento da capacidade estatal via cooperação em defesa. Apresentar variáveis domésticas em um modelo estrutural é uma armadinha ontológica, pelo problema da baixa capacidade explicativa associado às teorias reducionistas (WALTZ, 1979). Se fôssemos fazer uma lista das variáveis domésticas possíveis de influenciar nesse caso, nunca chegaríamos a uma lista final, haja vista a infinidade de possibilidades e de casos excepcionais. Contudo, essas duas variáveis nos parecem importantes como princípio geral, por isso sua inclusão aqui como sugestão de investigação futura.

\section{Referências Bibliográficas}

AXELROD, Robert. The Evolution of Cooperation. Nova York: Basic Books, 1984. 
; KEOHANE, Robert O. Achieving Cooperation Under Anarchy: Strategies and Institutions. World Politics, v. 38, n. 1, p. 226-254, Oct. 1985.

BROOKS, Stephen G.; IKENBERRY, G. John; WOHLFORTH, William C. Don't Come Home, America. The Case Against Retrenchment. International Securiy, v. 37, n. 3, p. 7-51, 2012/13.

BUZAN, Barry; LITTLE, Richard. Why International Relations has Failed as an Intellectual Project and What to do About It. Milleniun - Journal of International Studies, v. 30, n. 1, p. 19-39, 2001.

BUZAN, Barry; WÆVER, Ole. Regions and Powers. The Structure of International Security. Cambridge: Cambridge University Press, 2003.

CEPIK, Marco. Segurança regional e integração na América do Sul. In: CEPIK, M. (Org.). Segurança internacional: práticas, tendências e conceitos. São Paulo: Hucitec, 2010.

; MARTINS, José Miguel; ÁVILA, Fabrício. Armas estratégicas e poder no sistema internacional: o advento das armas de energia direta e seu impacto potencial sobre a guerra e a distribuição multipolar de capacidades. Contexto Internacional, v. 31, n. 1, p. 49-83, jan./abr. 2009.

COTTEY, Andrew; FORSTER, Anthony. Reshaping Defence Diplomacy: New Roles for Military Cooperation and Assistance. Adelphi Paper 365. The International Institute for Strategic Studies. Oxford: Oxford University Press, 2004.

DINIZ, Eugenio. Relacionamentos multilaterais na unipolaridade: uma discussão teórica realista. Contexto Internacional, v. 28, n. 2, p. 505-565, 2006.

DOYLE, Michael W.; SAMBANIS, Nicholas. United Nations Peace Operations: Making War and Building Peace. Princeton: Princeton University Press, 2006.

CREUTZFELDT, B. Theory Talk \#51: Yan Xuetong on Chinese Realism, the Tsinghua School of International Relations, and the Impossibility of Harmony. Theory Talks, 28 nov. 2012. Disponível em: <http://www.theory-talks. org/2012/11/theory-talk-51.html>. Acesso em: 15 mar. 2013.

DYSON, Tom. Neoclassical Realism and Defence Reform in Post-Cold War Europe. Londres: Palgrave Macmillian, 2010. 
Teoria Realista Ofensiva de Cooperação em

Defesa na Unipolaridade

FARIA, Carlos Aurélio P. de. Teaching and Research on Foreign Policy in the Field of International Relations of Brazil. Austral: Brazilian Journal of Strategy and International Relations, v. 1, n. 2, p. 95-128, Jul.-Dec. 2012.

GRIECO, Joseph. Cooperation Among Nations: Europe, America, and Non-tariff Barriers to Trade. Ithaca: Cornell University Press, 1990.

HAAS, Peter. Saving the Mediterranean: The Politics of International Environmental Cooperation. Nova York: Columbia University Press, 1990.

HERZ, John H. Idealist Internationalism and the Security Dilemma. World Politics, v. 2, n. 2, p. 157-180, Jan. 1950.

HOPF, Ted. The Promise of Constructivism in International Relations Theory. International Security, v. 23, n. 1, p. 171-200, 1998.

HYDE-PRICE, Adrian. European Security in the 21st Century: The Challenge of Multi-Polarity. Abingdon: Routledge, 2007.

JERVIS, Robert. Cooperation under the Security Dilemma. World Politics, v. 30, n. 2, p. 167-214, Jan. 1978.

. From Balance to Concert: A Study of International Security Cooperation. World Politics, v. 38, n. 1, p. 58-79, Oct. 1985.

Realism, Neolibealism and Cooperation. Understanding the Debate. International Security, v. 24, n. 1, p. 42-63, 1999.

KARACAZULU, Nilüfer; UZGÖREN, Elif. Explaining Social Constructivist Contributions to Security Studies. Perceptions, p. 27-48, Summer-Autumn 2007.

KECK, Zachary. Can Realists do P.R. Anymore? e-International Relations, 10 May 2012. Disponível em: <http://www.e-ir.info/2012/05/10/can-any-realists-do-p-r-anymore>. Acesso em: 15 mar. 2013.

KEOHANE, Robert O. After Hegemony: Cooperation and Discord in the World Political Economy. Princeton: Princeton University Press, 2005.

; MARTIN, Lisa. The Promise of Institutionalist Theory. International Security, v. 20, n. 1, p. 39-51, 1995. 
KRASNER, Stephen D. American Policy and Global Economic Satability. In: AVERY, W. P.; RAPKIN, D. P. (Ed.). America in a Changing World Political Economy. Nova York: Longman, 1982.

LAYNE, Christopher. The Unipolar Illusion Revisited: The Coming End of the United States' Unipolar Moment. International Security, v. 31, n. 2, p. 7-41, 2006.

LIPSON, Charles. International Cooperation in Economic and Security Affairs. World Politics, v. 37, Oct. 1984.

MACDONALD, Paul K.; PARENT, Joseph M. Graceful Decline? The Surprising Success of Great-Power Retrenchment. International Security, v. 35, n. 4, p. 7-44, 2011.

MATTES, Micaela. Reputation, Symmetry, and Alliance Design. International Organization, v. 66, p. 679-707, 2012.

MEARSHEIMER, John J. The False Promise of International Institutions. International Security, v. 19, n. 3, p. 5-49, 1994/95.

—. A Realist Reply. International Security, v. 20, n. 1, p. 62-70, 1995.

. The Tragedy of Great Power Politics. Nova York: W.W. Norton \& Company, 2001.

; WALT, Stephen M. Leaving Theory Behind: Why Hypothesis Testing Has Become Bad for IR. Faculty Research Working Paper Series, Harvard Kennedy School, Jan. 2013.

MILNER, Helen. Review Article. International Theories of Cooperation Among Nations: Strengths and Weaknesses. World Politics, v. 44, n. 3, p. 466-496, Apr. 1992.

MONTEIRO, Nuno P. Unrest Assured. Why Unipolarity Is not Peaceful. International Security, v. 36, n. 3, p. 9-40, 2011/12.

MORGENTHAU, Hans J. Alliances in Theory and Practice. In: WOLFERS, A. (Org.). Alliance Policy in the Cold War. Baltimore: The Johns Hopkins University Press, 1959.

A política entre as nações. A luta pelo poder e pela paz. Brasília: Editora da Universidade de Brasília, 2003. 
MORONEY, Jennifer D. P.; CRAGIN, Kim; GONS, Eric Stephen; GRILL, Beth; PETERS, John E.; SWANGER, Rachel M. International Cooperation with Partner Air Forces. Santa Mônica: Project Air Force, RAND Corporation, 2009.

MORONEY, Jennifer D. P.; GRISSOM, Adam; MARQUIS, Jefferson P. A Capabilities Based Strategy for Army Security Cooperation. Santa Mônica: Arroyo Center, RAND Corporation, 2007.

MUTHANNA, Colonel Ka. Enabling Military-to-Military Cooperation as a Foreign Policy Tool: Options for India. Nova Délhi: Knowledge World \& United Service Institution of India Centre for Research, 2006.

NINCIC, Miroslav. Renegade Regimes: Confronting Deviant Behavior in World Politics. Nova York: Columbia University Press, 2005.

. Getting What you Want. Positive Inducements in International Relations. International Security, v. 35, n. 1, p. 138-183, 2010.

ONUF, Nicholas. World of Our Making: Rules and Rule in Social Theory and International Relations. Columbia: University of South Carolina Press, 1989.

ORLIK, Tom; DAVIS, Bob. China's Economic Growth Slows Amid Global Turmoil. The Wall Street Journal, 13 Jul. 2012a. Disponível em: <http://online.wsj.com/article/SB10001424052702303740704577523202849328184. html>. Acesso em: 28 fev. 2013.

China's Growth Engine Declines. The Wall Street Journal, 17 Jan. 2012b. Disponível em: <http://online.wsj.com/article/SB1000142405297 0204555904577165593145006650.html>. Acesso em: 28 mar. 2013.

PAPE, Robert. Soft Balancing Against the United States. International Security, v. 30, n. 1, p. 7-45, 2005.

POSEN, Barry R. The European Security and Defence Policy: Response to Uni-Polarity. Security Studies, v. 15, n. 2, p. 149-186, 2006.

PROENÇA JR., Domício. Estudos estratégicos: fundamentos e situação presente. Trabalho apresentado no Painel sobre Strategic Studies Epistemology, Center for Hemispheric Defense Studies. Research and Education in Defense and Security Studies (REDES 2003). Santiago do Chile, 28-30 out. 2003.

REITER, Dan. Learning, Realism, and Alliances. The Weight of the Shadow of the Past. World Politics, v. 46, n. 4, p. 490-526, Jul. 1994. 
RESENDE-SANTOS, João. Neorealism, States and the Modern Mass Army. Cambridge: Cambridge University Press, 2007.

RUGGIE, John Gerard. The False Premise of Realism. International Security, v. 20, n. 1, p. 62-70, 1995.

SCHROEDER, Paul. Alliances, 1815-1945: Weapons of Power and Tools of Management. In: KNORR, K. (Org.). Historical Dimensions of National Security Problems. Lawrence: Allen Press, 1976. p. 227-262.

SCHWELLER, Randall L. Bandwagoning for Profit: Bringing the Revisionist State Back In. International Security, v. 19, n. 1, p. 72-107, 1994.

New Realist Research on Alliances: Refining Not Refuting Waltz's Balancing Proposition. The American Political Science Review, v. 91, n. 4, p. 927-930, 1997.

Deadly Imbalances: Tripolarity and Hitler's Strategy of World Conquest. Nova York: Columbia University Press, 1998.

SINGER, David J.; SMALL, Melvin. Formal Alliances, 1815-1939: A Quantitative Description. Journal of Peace Research, v. 3, n. 1, p. 1-32, 1966.

SNIDAL, Duncan. Relative Gains and the Pattern of International Cooperation. American Political Science Review, v. 85, n. 3, p. 701-726, Sep. 1991.

SNYDER, Glenn H. Alliance Theory: A Neorealist First Cut. In: ROTHSTEIN, R. L. The Evolution of Theory in International Relations. Columbia: University of South Carolina, 1991.

SUTTERLIN, James S. The United Nations and the Maintenance of International Security: A Challenge to Be Met. [s.1.]: Praeger, 1995.

TUCKER, Jonathan B. Partners and Rivals: A Model of International Collaboration in Advanced Technology. International Organization, v. 45, n. 1, p. 83-120, 1991.

URPELAINEN, Johannes. How Uncertainty about Outside Options Impedes International Cooperation. International Theory, v. 4, n. 1, p. 133-163, Mar. 2012.

US CONGRESS. Office of Technology Assessment (OTA). Arming our Allies: Cooperation and Competition in Defense Technology. OTA - ISC - 449. Washington: US Government Printing Office, May 1990. 
Teoria Realista Ofensiva de Cooperação em

Defesa na Unipolaridade

WALT, Stephen M. The Origin of Alliances. Ithaca: Cornell University Press, 1987.

A Model Disagreement. International Security, v. 24, n. 2, p. 115-130, 1999.

. Taming American Power: The Global Response to US Primacy. Nova York: Norton, 2005.

WALTZ, Kenneth N. Man, the State and War. A Theoretical Analysis. Nova York: Columbia University Press, 1959.

Theory of International Politics. Nova York: McGraw-Hill, 1979.

WENDT, Alexander. Anarchy is What States Make of it: The Social Construction of Power Politics. International Organization, v. 46, n. 2, p. 391-425, 1992.

WILKINS, Thomas S. Russo-Chinese Strategic Partnership: A New Form of Security Cooperation? Contemporary Security Policy, v. 29, n. 2, 2008.

"Alignment" not "Alliance" - The Shifting Paradigm of International Security Cooperation: Toward a Conceptual Taxonomy of Alignment. Review of International Studies, v. 38, p. 53 76, 2012.

WOHLFORTH, William C. The Stability of a Unipolar World. International Security, v. 24, n. 1, p. 5-41, 1999.

\section{Resumo}

\section{Teoria Realista Ofensiva de Cooperação em Defesa na Unipolarídade}

A teoria realista ofensiva de cooperação em defesa na unipolaridade busca compreender: (1) a motivação dos Estados para cooperar em defesa; (2) as variáveis independentes que afetam a cooperação em defesa; (3) um modelo amplo de cooperação em defesa que possa ser replicado em diferentes regiões do mundo. Na unipolaridade, tentativas de alteração das balanças de poder regionais serão punidas pelo sistema. A forma como os Estados pode- 


\section{Lucas Pereira Rezende}

rão maximizar o seu poder é a cooperação em defesa, que deve prover não apenas aumento da capacidade estatal individual, mas também elementos distributivos que não desencadeiem uma corrida armamentista no plano regional, nem um balanceamento offshore por parte da potência unipolar. A teoria sugere que novos tempos exigem novas formas de maximização de poder.

Palavras-chave: Teoria das Relações Internacionais - Cooperação em Defesa - Unipolaridade - Realismo Ofensivo

\section{Abstract}

\section{Offensive Realist Theory of Defence Cooperation under Unipolarity}

The offensive realist theory on defence cooperation under unipolarity aims to understand: (1) the state motivation to cooperate on defence; (2) the independent variables that affect defence cooperation; (3) a comprehensive defence cooperation model that can be replicated in different regions of the world. Under unipolarity, attempts to alter the regional balances of power will be punished by the system. The way states can maximise their power is through defence cooperation, which must provide not only the individual state capacity but also distributive elements that do not trigger an arms race on the regional aspect nor an offshore balancing from the unipole. The theory suggests that new times demand new ways of power maximisation.

Keywords: International Relations Theory - Defence Cooperation Unipolarity - Offensive Realism 